\title{
Electrochemical/Electrospray Mass Spectrometric Studies of Electrochemically Stimulated ATP Release from PP/ATP Films
}

\author{
Lidong Li and Chubao Huang \\ Department of Environmental Science \& Engineering, Tsinghua University, Beijing, China
}

Polypyrrole (PP)/adenosine triphosphate (ATP) was chosen as a conducting polymer/anionic drug model to serve as a bioactive releasing material for ATP. The process of ATP release from PP/ATP films was investigated for the first time by electrochemical electrospray ionization mass spectrometry (EC/ESMS). This technique allowed the simultaneous and direct detection of ATP and its related species during electrochemical release. In the experiments, suitable solvent conditions were found for both the electrochemical release and the electrospray mechanisms. EC/ESMS results showed that continuous potential cycles allowed a higher ATP release rate than potential steps. It was also found that the film thickness is an important factor affecting the rate and the amount of electrochemical ATP release. (J Am Soc Mass Spectrom 2007, 18, 919-926) (c) 2007 American Society for Mass Spectrometry

$\mathrm{W}$ e chose to study the adenosine $5^{\prime}$-triphosphate (ATP) release system because ATP is a very important component of biological systems. It plays an important role in energy storage and conversion in all living cells. The controlled release of ATP from conducting polymers has been studied by several groups, for example, by both Reynolds and Genies [1-15]. These groups used optical spectroscopic, potentiometric, and conductiometric methods to examine ATP release. Because ATP is easily incorporated into the matrix of polymers during the electropolymerization process, and is easily exchanged with anions in solution, it is possible to make an ATP release device for a clinical system. In addition, ATP ions are thought to be inert during hydrolytic cleavage in both synthesis and potential driven release, and thus electrodes modified with PP / ATP polymer films may be useful as ATP supply devices [7].

In the work reported by Reynolds [7], the electrochemically stimulated and spontaneous release of ATP from PP/ATP-modified electrodes was investigated by ultraviolet-visible (UV-vis) spectroscopy. The results showed that over a much shorter time period, appreciable amounts of ATP were released during potential cycling with a peak at $260 \mathrm{~nm}$. In contrast, the PP/ATP film was relatively stable to spontaneous ion-exchange processes using an open circuit. Genies reported that PP/ATP exhibits an ion dependent electrochemical response during cycling in various electrolyte solutions [8]. Two separate redox processes were observed from

Published online March 28, 2007

Address reprint requests to Dr. Lidong Li, Department of Environmental Science \& Engineering, Tsinghua University, Beijing,China.E-mail: lilidong@ mail.tsinghua.edu.cn the cyclic voltammogram (CV) of PP/ATP film (of 450-nm thickness, on a Pt button) cycled in $0.1 \mathrm{M} \mathrm{NaCl}$, NaPSS, and PVPy $\mathrm{HCl}$ solutions, respectively. The results showed that the more anodic redox process is suppressed when the film is cycled in NaPSS, whereas the more cathodic redox peaks disappear when cycled in PVPy $\cdot \mathrm{HCl}$, indicating that the more anodic redox process was associated with anion-dominant transport, and the more cathodic redox process, with cationdominant transport [11]. EQCM (electrochemical quartz crystal microbalance) studies showed that, in the initial cathodic redox process, the reduction was dominated by $\mathrm{Na}^{+}$penetration into the film. Subsequently, the diffusions of ATP sodium salt out of the film occurred with ease [7]. In the studies of Liljegren et al. [16], electrochemically controlled solid-phase extraction (EC-SPE), using conducting polymers (such as polypyrrole) as stationary phases, was demonstrated by coupling EC-SPE to electrospray ionization- or inductively coupled plasma-mass spectrometry (ESI-MS and ICP-MS, respectively) on line. The advantage of this relatively new technique was that both the extraction and desorption steps could be controlled merely by changing the applied potential of the conducting polymer-coated working electrode. In these experiments, the extraction of the negatively charged model analytes $\left[\mathrm{Fe}(\mathrm{CN})_{6}^{3-}\right.$ and $\mathrm{Br}^{-}$] was performed by applying a potential of $+800 \mathrm{mV}$ to the working electrode modified with polypyrrole, using the flow cell. At this potential, the polypyrrole was oxidized, becoming positively charged, which resulted in an electrosorption (extraction) of anions $\left[\mathrm{Fe}(\mathrm{CN})_{6}^{3-}\right.$ and $\left.\mathrm{Br}^{-}\right]$. The polypyrrole was subsequently reduced to its neutral state by the application of a potential of $-800 \mathrm{mV}$. During the latter step, anions 
were again expelled (desorbed) from the stationary phase.

Previous studies on ATP release in PP/ATP system (electrochemically triggered release and spontaneous release) included analysis by $\mathrm{CV}$, spectroscopy or EQCM; however, these techniques cannot give us detailed on-line information of electrochemical ATP release in the cell. To obtain real-time information in the electrochemical cell, electrospray to couple electrochemistry (EC) on-line with MS has been developedthat is, electrochemical electrospray mass spectrometry (EC/ESMS) [16-26]. In this technique, a high voltage $(\sim 4 \mathrm{kV})$ is used in ESI/MS to ionize and transfer the analyte mist into the mass spectrometer. The advantages of the high sensitivity and selectivity of mass spectrometry have long been recognized. Therefore, it is a very useful technique for detecting trace levels of analytes in the gas phase. In contrast to many ionization methods, such as EI and CI, electrospray (ES) is a very "soft" ionization method. It has the advantages of causing minimal decomposition and fragmentation of ions, gas-phase reactions of the analytes are minimal, and a wider variety of solvents can be used. Thus, the technique (EC/ESMS) has been applied to the study of organic molecules and to the identification of charged inorganic and organometallic species dissolved in organic solvents.

In this study, for the first time, we used EC/ESMS to investigate electrochemical ATP release processes from PP/ATP films. This technique allowed the simultaneous and direct detection of ATP and its related species during electrochemical release. By using EC/ ESMS, we could precisely monitor the on-line ATP release profiles. In our research, electrochemical ATP release under three types of controlled potential was carried out. The electrochemical ATP release as a function of film thickness was also investigated in detail. The results show that the film thickness is an important factor affecting both the rate and the amount of electrochemical ATP release as previous studies suggested [11].

\section{Experimental}

\section{Chemicals and Solutions}

Adenosine 5'-triphosphate, disodium salt hydrate $(99 \%)$, pyrrole, $(98 \%)$, and ammonium acetate $(99 \%)$ were purchased from Aldrich Chemical Co. (Milwaukee, WI, USA). All salts were used as received. Electrolyte solutions of $2 \mathrm{mM} \mathrm{NH}_{4} \mathrm{Ac}$ were prepared in freshly distilled $\mathrm{CH}_{3} \mathrm{CN}$, deionized water, and $\mathrm{Et}_{4} \mathrm{~N}$ (vol/vol/ vol $=35 / 65 / 0.1$ ).

\section{Instrumental}

A VG Trios 2000 (VG Biotech, Altrincham, UK) quadrupole mass spectrometer with VG electrospray source was used in these experiments. Here all the mass spectra were acquired in negative-ion mode coadding
30 scans at a scan rate of 0.25 scans/s. The ES tip voltage was $-4.10 \mathrm{kV}$, the source temperature was kept at $110^{\circ} \mathrm{C}$, and the cone voltage was $20 \mathrm{~V}$.

A custom-built electrochemical cell was made from a cylindrical Pyrex ${ }^{\circledR}$ tube (6 mm in diameter) with the solution flowing around the working gold disk electrode ( $3 \mathrm{~mm}$ in diameter) into a cupped Pyrex ${ }^{\circledR}$ collection tube. This cupped collection assembly led to the electrospray emitter through a fused silica capillary with $14 \mathrm{~s}$ of transfer time $\left(2.3 \times 10^{-3} \mathrm{~mL}\right.$ of dead volume). A platinum mesh was used as counter electrode. $\mathrm{An} \mathrm{Ag} / \mathrm{AgCl}$ wire was used as the reference electrode, which was connected to the cell through a double salt bridge. The distance between working electrode and counter electrode was about $5 \mathrm{~mm}$. Before use, the electrodes were cleaned by rinsing sequentially with distilled water, hydrofluoric acid $49 \%$, piranha solution, distilled water, HPLC-grade methanol, and fresh acetonitrile. The electrochemical cell is shown in Figure ${ }^{\circ} 1$.

A model CV-27 potentiostat [Bioanalytical Systems (BAS), West Lafayette, IN, USA] was used to apply potentials to the electrochemical cell and electrosynthesize the PP / ATP conducting polymer. All potentials are quoted versus aqueous $\mathrm{Ag} / \mathrm{AgCl}$. We held the potential at $0.8 \mathrm{~V}$ in the $0.1 \mathrm{M}$ pyrrole and $20 \mathrm{mM}$ ATP solution for a given time for PP/ATP film synthesis. The potential cycling ranged from 0.0 to $-1.1 \mathrm{~V}$ at a scan rate of $10 \mathrm{mV} / \mathrm{s}$; the potential step ranged from 0 to $-1.1 \mathrm{~V}$ with the potential first at $0 \mathrm{~V}$ for $1 \mathrm{~min}$, and then at -1.1 $\mathrm{V}$ for another $1 \mathrm{~min}$. The entire electrochemical cell was maintained at room temperature. A BAS $\varepsilon$-EC potentiostat was used to obtain conventional CV for comparison purposes.

A Series 74,900 syringe pump (Cole-Palmer, Vernon Hills, IL, USA) with a flow rate of $0.6 \mathrm{~mL} / \mathrm{h}$ was used to provide the constant mobile phase and produce the spray. To electrically isolate the electrochemical cell from the electrospray tip potential, the cell was connected to the electrospray probe tip through a 300- to 350-mm-long 0.1-mm ID untreated silica capillary, which caused $14 \mathrm{~s}$ of delay time to the electrospray emitter.

\section{Results and Discussion}

\section{Synthesis of PP/ATP Film}

In our experiments, the film thicknesses were calculated by $^{\circ}$ the ${ }^{\circ}$ charge ${ }^{\circ}$ passed ${ }^{\circ}$ during ${ }^{\circ}$ electropolymerization ${ }^{\circ}[8]$. For an example, a gold electrode with a PP/ATP film was prepared potentiostatically from $0.1 \mathrm{M}$ pyrrole in $20 \mathrm{mM}$ ATP aqueous solutions at $+0.8 \mathrm{~V}$ (versus $\mathrm{Ag} /$ $\mathrm{AgCl}$ ) for $10 \mathrm{~min}$. From chronoamperometry of film synthesis process, the charge passed was recorded as $44.6 \mathrm{mC}$. Because the electrode surface area is $0.07 \mathrm{~cm}^{2}$, the charge density can be calculated as $637.5 \mathrm{mC} / \mathrm{cm}^{2}$. The film was prepared on the electrode surface with estimated thickness of $2.5 \mu \mathrm{m}$ based on the assumption 


\section{Reference Electrode}

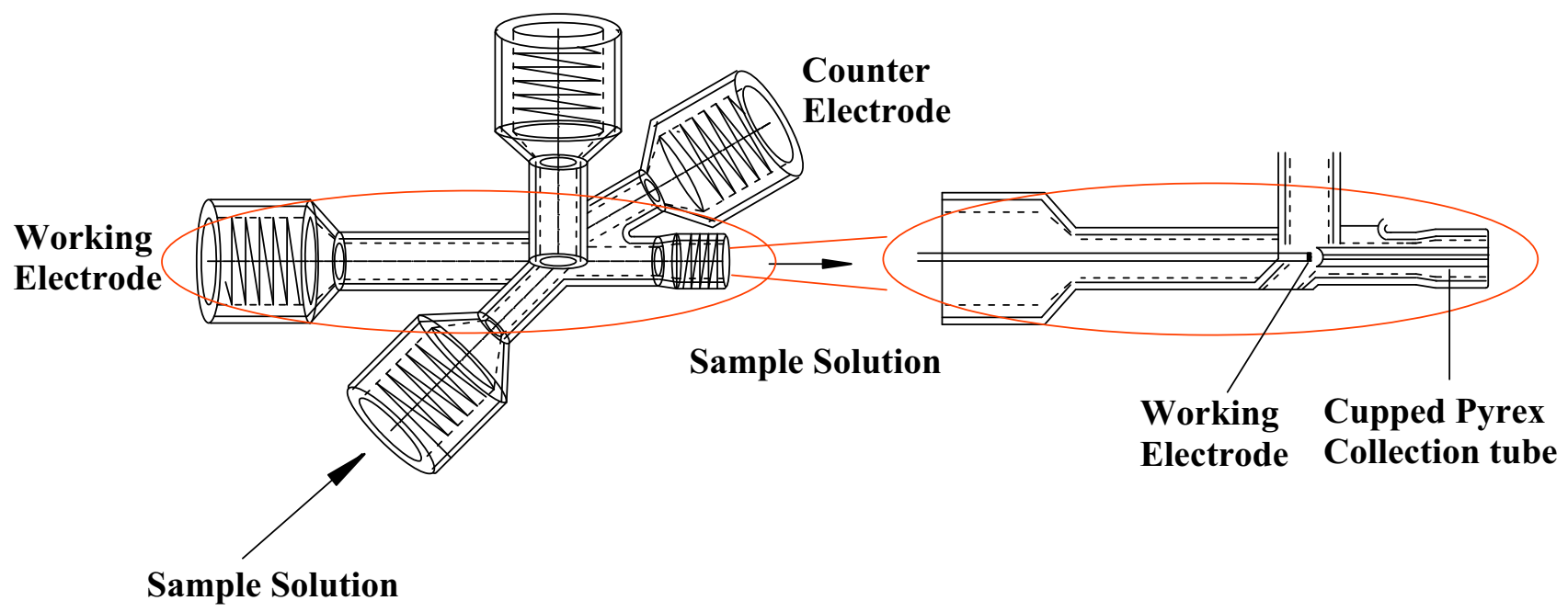

Figure 1. Diagram of electrochemical cell.

that $255^{\circ} \mathrm{mC} / \mathrm{cm}^{2 \circ}$ gives $1-\mu \mathrm{m}$ film thickness 98 ]. ${ }^{\circ}$ Because the doping level of PP/ATP was 0.27 in the above synthesis $^{\circ}$ solution $^{\circ}[7],{ }^{\circ} 44.6^{\circ} \mathrm{mC}^{\circ}$ electropolymerization charge corresponded to $5.3 \mathrm{mC}$ doping charge from ATP tri-anions; as a result, $1.83 \times 10^{-8}$ moles of ATP tri-anions were doped in the matrix of PP/ATP film.

\section{Selection of Suitable Conditions for the Detection of ATP by ESMS}

One difficulty in implementing ESMS is the selection of suitable conditions for the detection of ATP. In previous works on ATP release, all experiments were carried out in aqueous solution. However, a pure aqueous solution is not suitable for electrospray because the electric field required for the onset of electrospray increases with the surface tension of the solvent. Water has very high surface tension, which requires high onset fields, and these fields can lead to electrical discharges that partially suppress the ES process. Therefore, $100 \% \mathrm{H}_{2} \mathrm{O}$ is not $^{\circ} \mathrm{a}^{\circ} \operatorname{good}^{\circ}$ solvent $^{\circ}$ choice $^{\circ}$ for $^{\circ} \mathrm{ESMS}^{\circ}$ [27]. In ${ }^{\circ}$ addition, in our experiments, we found that pure water does not form a good spray from the capillary tip. To improve the signal of possible released ATP, we mixed water with an organic solvent, such as acetonitrile. The most efficient system for good ionization of the compounds of interest (ATP, ADP, AMP, etc.) was the mixture of acetonitrile/water/triethylamine (35/65/0.1 vol/vol/ vol). Before mixing with acetonitrile, the $\mathrm{pH}$ of the aqueous solution was 7.6. In this system, the addition of the $\mathrm{Et}_{3} \mathrm{~N}$ (neutral) helped to increase the $\mathrm{pH}$ without the addition of sodium ions (addition of $\mathrm{NaOH}$ ). These might decrease the signal of analyte arising from the increased electrolyte concentration, leading to the suppression of analyte signal, because an electrospray ion source is analogous to a controlled-

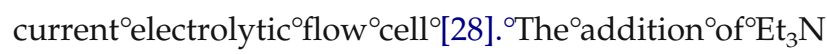
not only increased the ionization of the nucleotide phosphates but also decreased the formation of sodium ion adducts from $\mathrm{Na}_{4} \mathrm{ATP}$. This explains why mostly $\mathrm{H}_{3} \mathrm{ATP}^{-}$was observed.

The most difficult problem coupling electrochemistry on-line with ESMS is that most traditional supporting electrolytes for common electrochemistry are not suitable for electrospray mass spectrometry. For example, tetraalkylammonium perchlorates, sodium perchlorate, and sodium chloride would give rise to very strong background peaks, thus resulting in the suppression of the analyte signal. To optimize the supporting electrolyte used in EC/ESMS for the ATP release system, ESMS measurements of solutions $\left(\mathrm{CH}_{3} \mathrm{CN} / \mathrm{H}_{2} \mathrm{O} / \mathrm{Et}_{3} \mathrm{~N}\right.$ 35/65/0.1 vol/vol/vol) with different supporting electrolytes were carried out. The results showed that ammonium acetate is the best $^{\circ}$ electrolyte $^{\circ}$ in $^{\circ}$ this $^{\circ}$ system $^{\circ}$ Figure $^{\circ} 2^{\circ}$ shows $^{\circ}$ an ESMS mass spectrum of $1 \mathrm{mM} \mathrm{Na}_{2} \mathrm{H}_{2} \mathrm{ATP}$ with $1 \mathrm{mM}$ $\mathrm{NH}_{4} \mathrm{Ac}$ as supporting electrolyte. It gave us a very strong molecular ion species signal at $\mathrm{m} / \mathrm{z} 506$. The $\mathrm{m} / \mathrm{z}$ 506 and 528 were attributed to $\left(\mathrm{H}_{3} \mathrm{ATP}\right)^{-}$and ATP plus

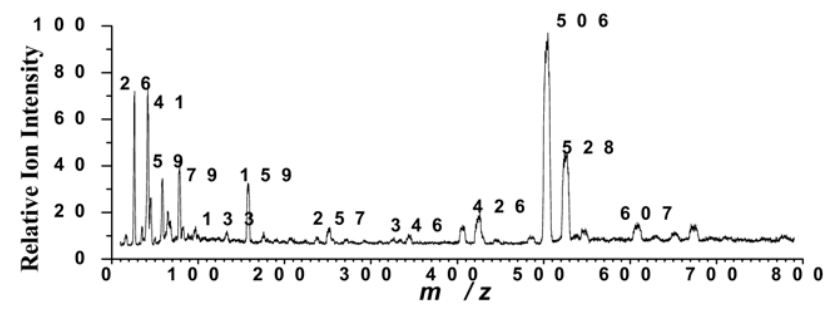

Figure 2. Negative ion ESMS of $1 \mathrm{mM} \mathrm{Na}_{2} \mathrm{H}_{2} \mathrm{ATP}$ in acetonitrile/ water/triethylamine $(\mathrm{vol} / \mathrm{vol} / \mathrm{vol}=35 / 65 / 0.1)$ solution, with electrolyte $1 \mathrm{mM} \mathrm{NH} \mathrm{NH}_{4} \mathrm{Ac}$. Flow rate $0.6 \mathrm{~mL} / \mathrm{h}$; source temperature $110^{\circ} \mathrm{C}$. 

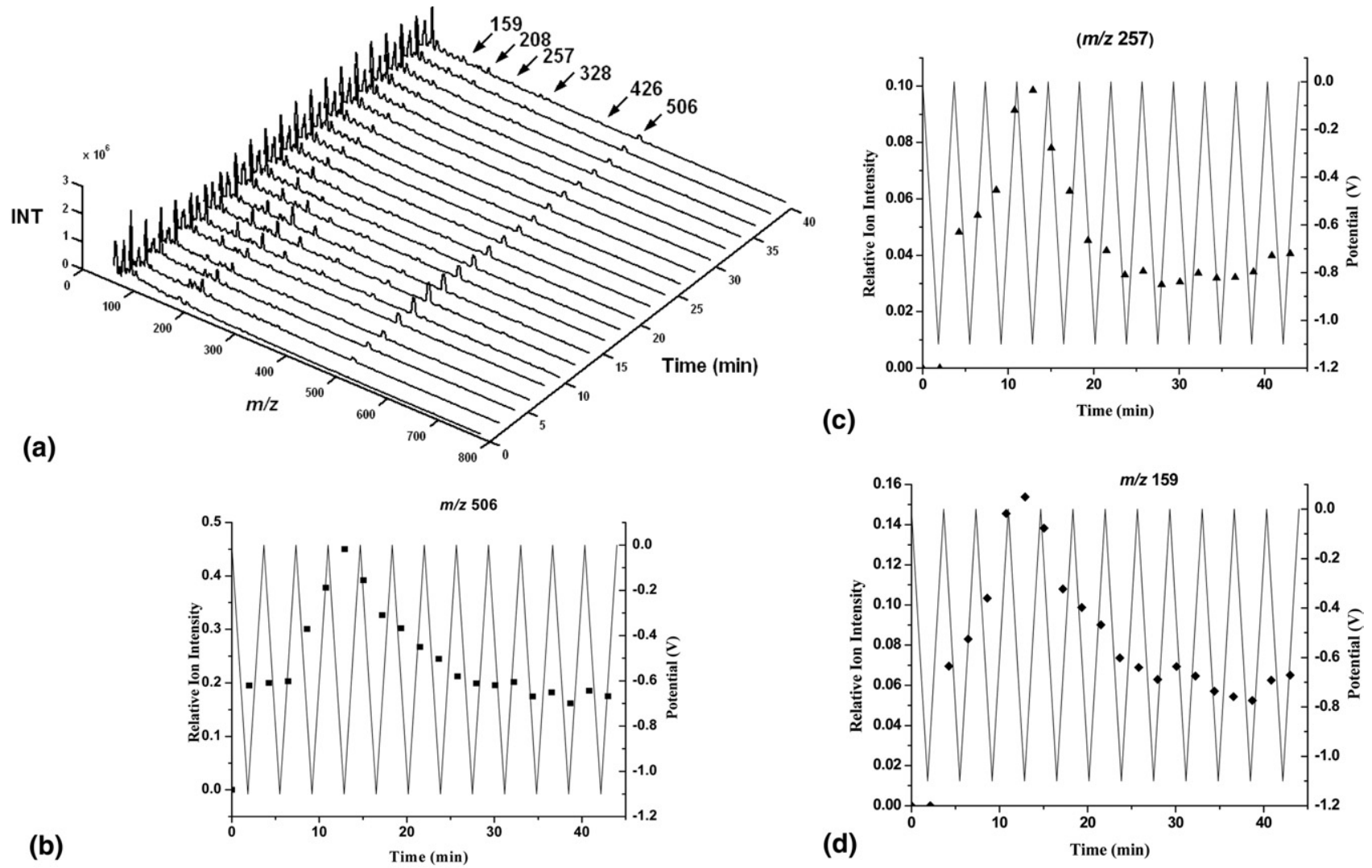

(c)

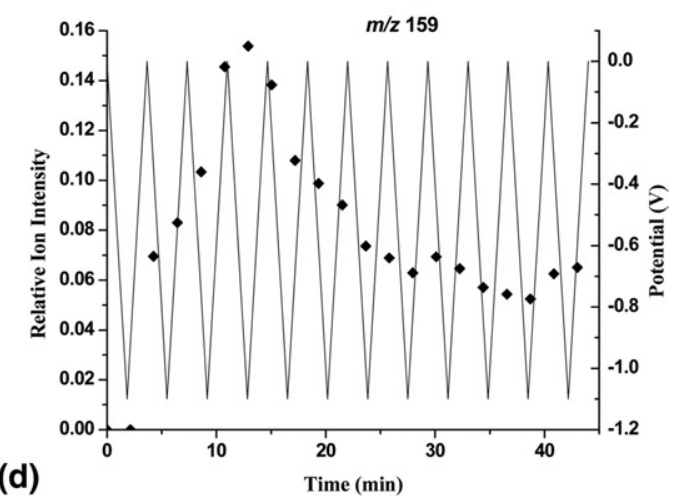

Figure 3. (a) Negative ion on-line EC/ESMS as a function of time. $m / z 506,\left(\mathrm{H}_{3} \mathrm{ATP}\right)^{-} ; \mathrm{m} / \mathrm{z} 426$ $\left(\mathrm{H}_{2} \mathrm{ADP}\right)^{-} ; \mathrm{m} / \mathrm{z} 328,\left(\mathrm{HAMP}-\mathrm{H}_{2} \mathrm{O}\right)^{-} ; \mathrm{m} / \mathrm{z} 257, \mathrm{H}_{3} \mathrm{P}_{3} \mathrm{O}_{10}^{-} ; \mathrm{m} / \mathrm{z} 208,\left[\mathrm{H}_{3} \mathrm{ATP} \cdot\left(\mathrm{CH}_{3} \mathrm{COO}\right)_{2}\right]^{3-} ; \mathrm{m} / \mathrm{z} 159$, $\mathrm{HP}_{2} \mathrm{O}_{6}^{-}$. Flow rate $0.6 \mathrm{~mL} / \mathrm{h}$; source temperature $110^{\circ} \mathrm{C}$. Potential cycling from 0 to $-1.1 \mathrm{~V}, \nu=10$ $\mathrm{mV} / \mathrm{s}$ ( $\sim 5-\mu \mathrm{m}$-thick PP/ATP film on the gold electrode). (b) Time-resolved relative ion intensity responses for $\mathrm{m} / \mathrm{z}$ 506, (c) $\mathrm{m} / \mathrm{z}$ 257, (d) $\mathrm{m} / \mathrm{z} 159$ obtained from EC/ESMS experiments (on-line electrolysis cycling from 0 to $-1.1 \mathrm{~V}$, scan rate $10 \mathrm{mV} / \mathrm{s}$ ) in which PP/ATP film was reduced in the optimal solution ( $\sim 5-\mu \mathrm{m}$-thick PP/ATP film on the gold electrode).

one sodium atom $\left(\mathrm{NaH}_{2} \mathrm{ATP}\right)^{-} ; \mathrm{m} / z 426$ and 448 were attributed to $\left(\mathrm{H}_{2} \mathrm{ADP}\right)^{-}$ion and $\mathrm{ADP}$ plus one sodium atom (NaHADP) ${ }^{-} ; m / z 346$ and 328 were attributed to $(\mathrm{HAMP})^{-}$and $\left(\mathrm{HAMP}-\mathrm{H}_{2} \mathrm{O}\right)^{-}$, respectively. The observation of $\mathrm{ADP}$ and $\mathrm{AMP}$ species in the mass spectra arose from the fragmentation of ATP ions that took place during the electrospray process. In addition, other fragment ion species at $m / z 257,159,97$, and 79 were shown ${ }^{\circ}{ }^{\circ}{ }^{\circ}$ the ${ }^{\circ}$ negative-ion ${ }^{\circ}$ mass $^{\circ}$ spectrum. $^{\circ}{ }^{\circ}{ }^{\circ}{ }^{\circ}$ Figure $^{\circ} 2$, $\mathrm{m} / \mathrm{z} 181$ was probably attributable to $\mathrm{m} / \mathrm{z} 159$ plus one sodium atom minus one proton, $\left(\mathrm{NaP}_{2} \mathrm{O}_{6}\right)^{-}$. There was a small peak at $m / z 133$, which was attributed to adenine $\mathrm{C}_{5} \mathrm{~N}_{5} \mathrm{H}_{3}^{-}$, a fragment ion of ATP. A peak at $m / z 607$ was attributed to the clusters of $\left(\mathrm{ATP} \cdot \mathrm{Et}_{3} \mathrm{~N}\right)^{-}$. We did not expect to see $\mathrm{ATP}^{-2}$ or $\mathrm{ATP}^{-3}$ anions because the $\mathrm{pK}_{\mathrm{a}}$ of the phosphates increases significantly from -1 to -2 to -3 and because of the instability resulting from a large amount of charge present in such a localized area of the molecule.

Moreover, the UV results under this condition verified that ATP is still electrochemically released very well. Therefore, the most efficient system we found for ATP detection by ESMS is $\mathrm{CH}_{3} \mathrm{CN} / \mathrm{H}_{2} \mathrm{O} / \mathrm{Et}_{3} \mathrm{~N}$ 35/65/ $0.1 \mathrm{vol} / \mathrm{vol} / \mathrm{vol}$ with $2 \mathrm{mM} \mathrm{NH}_{4}$ Ac.

\section{ESMS Results of Electrochemical ATP Release}

It has been suggested that the amount and rate of ATP release can be tuned by carefully controlling the potential $^{\circ}[1] .^{\circ}$ In $^{\circ}$ our $^{\circ}$ experiments, ${ }^{\circ}$ the ${ }^{\circ}$ electrochemical ${ }^{\circ}$ ATP release under three types of controlled potentials was investigated.

\section{On-line EC/ESMS Results of Potential Cycling}

In the experiment, ATP was electrochemically released from PP/ATP film in the above solvent system. Before the experiment, the polymer was oxidized in the synthesis process; the oxidation reaction is shown as follows:

$$
\begin{aligned}
& \text { nPyrrole } \stackrel{-\mathrm{ne}^{-}}{\longrightarrow} \text { oxidized polypyrrole }(\mathrm{PP})^{+} \\
& 3 \mathrm{PP}^{+}+\mathrm{HATP}^{3-} \longrightarrow\left(\mathrm{PP}^{+}\right)_{3} \cdot \mathrm{HATP}^{3-}
\end{aligned}
$$

The electrochemical release of ATP from PP/ATP film was generated by applying potential cycling with a range of 0.0 to $-1.1 \mathrm{~V}$ at a scan rate of $10 \mathrm{mV} / \mathrm{s}$. ATP was released out of the film as a result of the reduction 

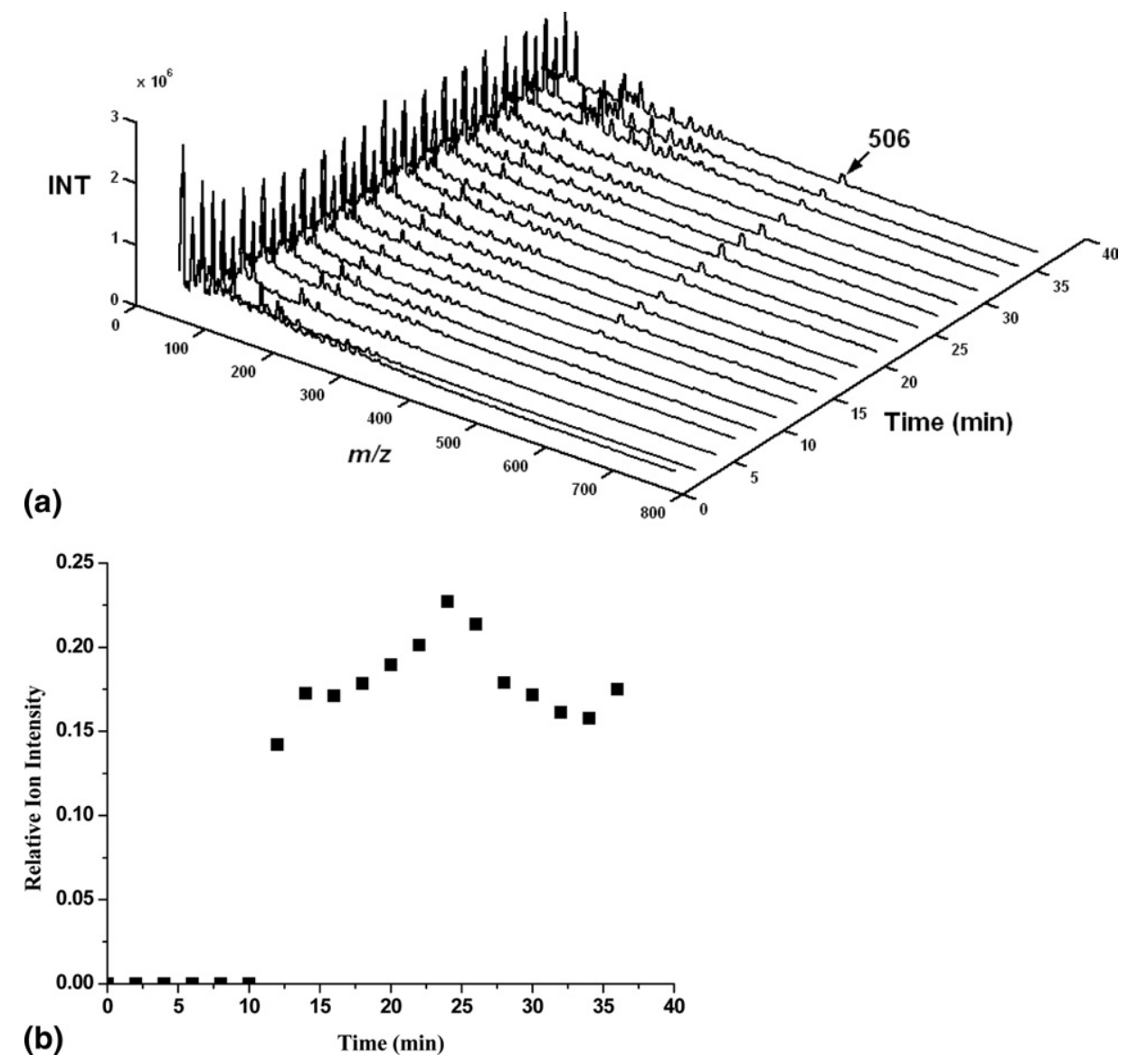

Figure 4. (a) EC/ESMS negative mass spectra as a function of time. Flow rate $0.6 \mathrm{~mL} / \mathrm{h}$; source temperature $110^{\circ} \mathrm{C}$. Holding the potential at $-1.1 \mathrm{~V}(\sim 5-\mu \mathrm{m}$-thick PP/ATP film on the gold electrode). (b) Time-resolved relative ion intensity responses for $\mathrm{m} / \mathrm{z} 506$ obtained from EC/ESMS experiments (on-line electrolysis holding potential at $-1.1 \mathrm{~V}$ ) in which PP/ATP film was reduced in the optimal solution ( $\sim 5-\mu$ m-thick PP/ATP film on the gold electrode).

of polypyrrole during the negative potential scan (0 to $-1.1 \mathrm{~V})$. The reduction reaction is shown as follows:

$$
3 \mathrm{PP}^{+} \cdot \mathrm{HATP}^{3-} \stackrel{+3 \mathrm{e}^{-}}{\longrightarrow}(\mathrm{PP})_{3}+\mathrm{HATP}^{3-}
$$

From the cyclic voltammogram in our experiments, polypyrrole was still released during the reverse scan $(-1.1$ to $-0.6 \mathrm{~V})$. From $-0.6 \mathrm{~V}$ to even more positive potential $(0 \mathrm{~V})$, a little oxidation current occurred, indicating polypyrrole started to be oxidized. The oxidation reaction is shown as

$$
(\mathrm{PP})_{3}+\mathrm{HATP}^{3-} \stackrel{-3 \mathrm{e}^{-}}{\longrightarrow} 3 \mathrm{PP}^{+} \cdot \mathrm{HATP}^{3-}
$$

To obtain the time profile of released ATP, we performed electrochemical reactions on-line, where the species generated in the cell flowed into the electrospray probe and were monitored through mass spectrometry. Mass spectra as a function of time are shown in $^{\circ}$ Figure $^{\circ} 3 a^{\circ} .^{\circ} \mathrm{We}^{\circ}$ observed $^{\circ} \mathrm{a}^{\circ}$ small $^{\circ}$ indicative ${ }^{\circ}$ peak $^{\circ}$ of ATP $m / z 506$ occurring in the second spectrum taken after application of potential cycling for $2 \mathrm{~min}$, indicat- ing that the delay time was only 2 min long. Here we ignored the transfer time between the electrochemical cell and electrospray tip (14 s). The peak grew quickly, up to about $13 \mathrm{~min}$, where it reached its maximum value and then gradually decreased almost to zero. From this 3-D plot, it was observed that the intensity of several other peaks also varied with time.

Figure ${ }^{\circ} 3 b^{\circ},{ }^{\circ},{ }^{\circ} d^{\circ}$ show $^{\circ}$ the $e^{\circ}$ plots $^{\circ}$ of ${ }^{\circ}$ the ${ }^{\circ}$ relative ${ }^{\circ}$ ion intensity for the molecular ion and fragment species of ATP at $m / z 506,257$, and 159 obtained as a function of time in a potential cycling experiment. The potential as a function of time was also plotted. In general, the type of relationship between ion abundance and time for release of all the ATP species is similar. In the middle of the fourth cycle, at a potential of $-1.1 \mathrm{~V}$, the polymer was fully reduced and the ion intensity had a strongest value. The ion intensity started to increase sharply at 6 min, until $13 \mathrm{~min}$, then decreased slowly thereafter, which indicates that for all the ATP species, their associated mass intensity reached its maximum value at about $13 \mathrm{~min}$. By further experiments, we found that no significant release occurred above a given gate potential (about $-0.6 \mathrm{~V}$ ). 

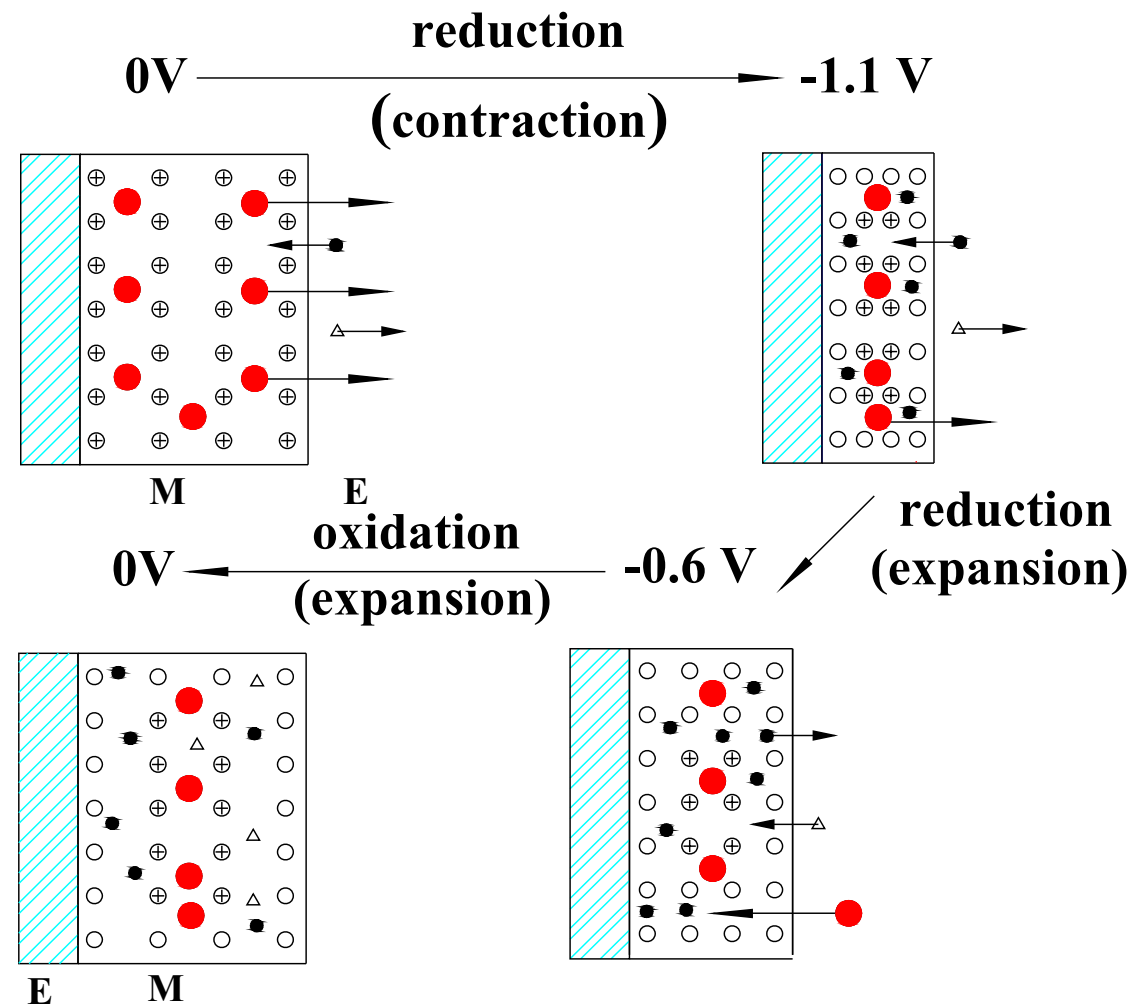

\section{- $\mathrm{H}_{3}$ ATP $^{-} \oplus$ Pyrrole $^{+} \circ$ Pyrrole $^{-\mathrm{NH}_{4}^{+}} \Delta \mathrm{Ac}^{-}$}

Figure 5. Schematic diagram showing the control of ion flux and electrochemically stimulated ATP release from PP/ATP films. E, electrode; $M$, membrane.

\section{On-line EC/ESMS Results of Potential Step}

Another EC/ESMS on-line experiment was done as follows: the experiment was performed with exactly the same solution and flow rate, except the potential was held at $\mathrm{E}=-1.1 \mathrm{~V}$ instead of potential cycling. The

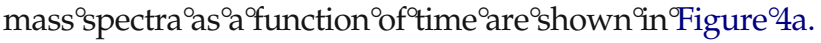
Among the first six mass spectra, no ATP molecular ion peak at $\mathrm{m} / \mathrm{z} 506$ was observed. At $10 \mathrm{~min}$, a peak appeared at $\mathrm{m} / \mathrm{z} 506$, reached its maximum value at about $24 \mathrm{~min}$, and then decreased slowly, indicating that a fixed amount was released. The release profile of ATP relative ion intensities versus time is shown in

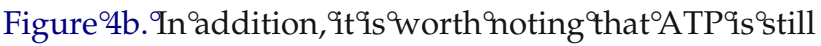
released slowly even after $40 \mathrm{~min}$. This is likely attributable to structural changes that occur in the polymer during redox switching and the multi-ionic nature of the dopant. It has been suggested that the physics associated with this unusual behavior arises from the inhibited diffusion process that occurs as a consequence of initial pore restriction in the first step of the release [29]..${ }^{\circ}$ Compared ${ }^{\circ}$ with $^{\circ}$ Figure $^{\circ} 3,{ }^{\circ}$ we $^{\circ}$ saw $^{\circ}$ that ${ }^{\circ} \mathrm{ATP}^{\circ}$ diffused out of the membrane later than in the potential cycling experiment. The intensity was smaller as well, which is in accordance with the results from the literature $[7,28]$. Hereagain, the transfer time $^{\circ}$ of 14 s $^{\circ}$ was also ignored as negligible, when compared with the large delay time (10 $\mathrm{min})$.

\section{On-line EC/ESMS Results of Repeated Potential Steps}

We repeatedly stepped the electrode potential down from 0 to $-1.1 \mathrm{~V}$ for $1 \mathrm{~min}$, and then up to $0 \mathrm{~V}$ for $1 \mathrm{~min}$, while monitoring the ion signal. After $45 \mathrm{~min}$, we did not observe any ATP $(m / z 506)$ release. This indicated that potential cycling was the best way to release ATP out of the film. We suggest that potential steps may have resulted in polymer films lacking porosity, so that anions could not escape. In this case, cations compensate more easily for charge balance.

From our experiments, it was observed that repeated slow potential cycling gave a higher ATP release rate than did a sustained single potential step of equal range, a result in accordance with that from the study reported by $^{\circ}$ Pyo 97$]$. This 9 phenomenon ${ }^{\circ}$ can ${ }^{\circ} e^{\circ}$ explained as follows. Cathodic reduction of the polymer film tends to expel the ATP anions out of the film. During the negative potential scan from 0 to $-1.1 \mathrm{~V}$, the film composed mainly of $\mathrm{PP}^{+}$is supposed to undergo slight contraction because of a pore-closing process occurring as increasingly more ATP anions are pushed out of the $\mathrm{PP}^{\circ}$ backbone ${ }^{\circ}$ into $^{\circ}$ the ${ }^{\circ}$ solution ${ }^{\circ}[29]^{\circ} .^{\circ}{ }^{\circ}{ }^{\circ}$ the ${ }^{\circ}$ meantime, some $\mathrm{NH}_{4}^{+}$ions in the solution phase are getting into the film, whereas $\mathrm{Ac}^{-}$ions are moving in the opposite direction. During the reverse scan of the potential, the 

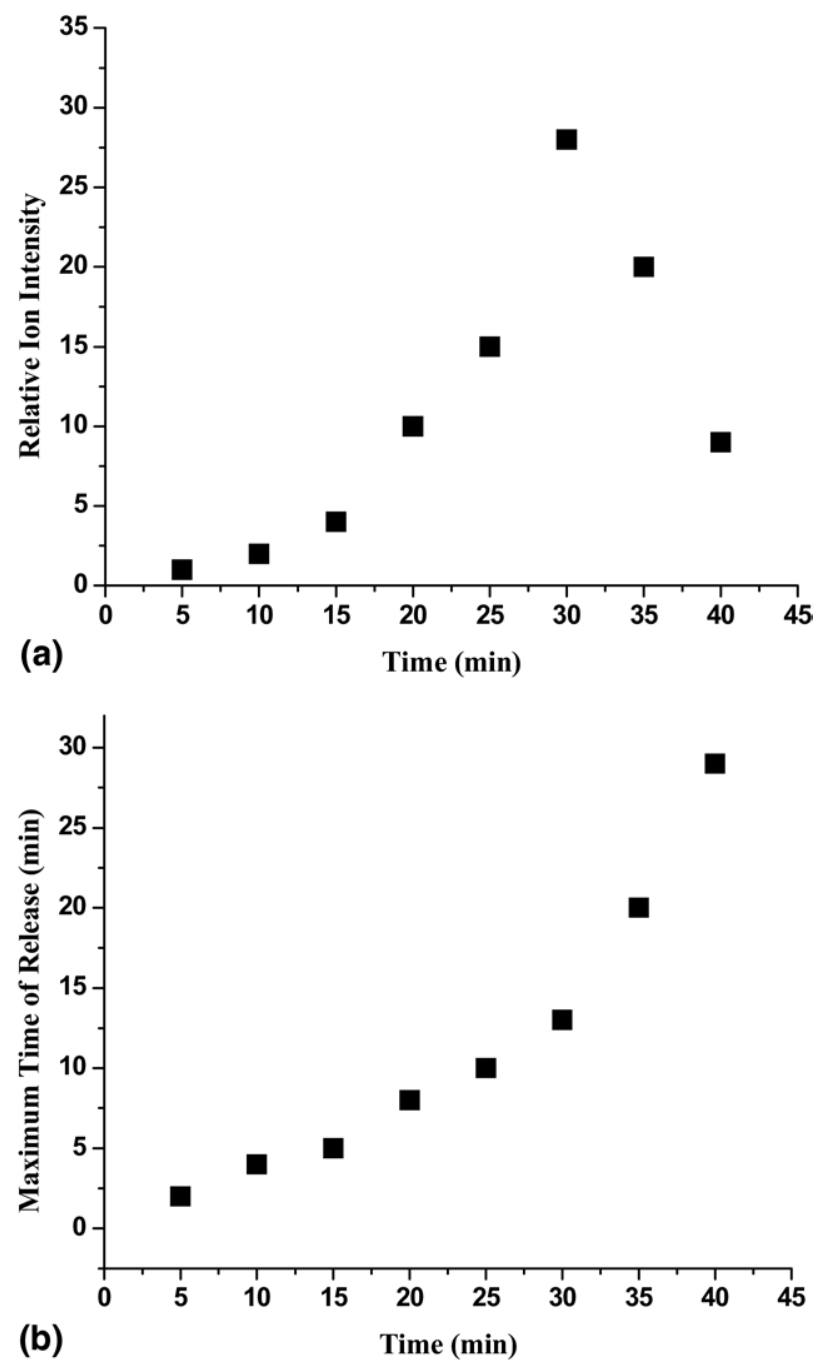

Figure 6. (a) Profile of relative ion intensity of $\mathrm{H}_{3} \mathrm{ATP}^{-}(\mathrm{m} / \mathrm{z} 506)$ at the largest detected amount from EC/ESMS versus synthesis time when we made the film. (b) Profile of time at which the intensity of $\mathrm{H}_{3} \mathrm{ATP}^{-}$reaches its maximum value versus synthesis time.

$\mathrm{PP}^{+}$matrix is likely to undergo expansion instead of contraction. However, for the first part of the reverse scan from -1.1 to $-0.6 \mathrm{~V}$, the current remains cathodic as observed in the CV. This means the reduction of polypyrrole is still in continuation, although to a lesser and decreasing extent and, consequently, some more ATP anions are still expelled from the film. Only later in the more positive potential range from -0.6 to $0 \mathrm{~V}$, there appears a very small anodic current, probably attributable to the reoxidation of the partly reduced polypyrrole. Yet, as a result of the relatively low concentration of the ATP anion in the vicinity of the polymer electrode, a very small amount of ATP anions might be reincorporated into the film. As a result, for the whole cycle of the potential scan, many more ATP anions are released than are reincorporated. Thus we might explain why repeated slow potential cycling is more effective than single potential step in releasing
ATP anions from the polymer film. The polypyrrole film doped with ATP is somewhat analogous to a sponge soaked with water. If we repeatedly squeeze it and release it for many times, more water will be squeezed out than just squeezing it once and holding the $^{\circ}$ squeeze $^{\circ}$ Figure $^{\circ} 5^{\circ}$ is $^{\circ}$ a $^{\circ}$ schematic $^{\circ}$ diagram $^{\circ}$ of ${ }^{\circ}$ a PP /ATP film and the flow of ions under electrochemically ${ }^{\circ}$ stimulated ${ }^{\circ}$ ATP ${ }^{\circ}$ release. ${ }^{\circ}{ }^{\circ}{ }^{\circ}$ Figure ${ }^{\circ} 5{ }^{\circ}$ we $^{\circ}$ assume ${ }^{\circ}$ an ATP doping level of roughly $25 \%$, which corresponds to one $^{\circ} \mathrm{ATP}^{\circ}$ anion $^{\circ}$ per $^{\circ}$ four ${ }^{\circ}$ pyrrole ${ }^{\circ}$ repeat $^{\circ}$ units $^{\circ}[7]$.

\section{Electrochemical ATP Release as a Function of Film Thickness}

We observed that the amount of released ATP from PP/ATP film was dependent on film thickness. The longer we electropolymerized a PP/ATP film, the thicker the film we obtained. In our experiments, we polymerized films over different times, from 5 and 10 min, up to $40 \mathrm{~min}$, which corresponded to film thicknesses of $1.25,2.5$, and $10 \mu \mathrm{m}$, respectively. We then electrochemically released the ATP and recorded the strongest peak intensity in the mass spectrum for each film ${ }^{\circ}$ thickness. ${ }^{\circ}$ Figure $^{\circ} 6 a^{\circ}$ shows ${ }^{\circ}$ the ${ }^{\circ}$ profile $^{\circ}$ of ${ }^{\circ}$ relative ion intensity of $\mathrm{H}_{3} \mathrm{ATP}^{-}(\mathrm{m} / \mathrm{z} 506)$ versus film synthesis time. The points are normalized to a film polymerized for ${ }^{\circ}{ }^{\circ} \mathrm{min}$. ${ }^{\circ}$ Figure ${ }^{\circ} 6 b^{\circ}$ shows $^{\circ}$ the $e^{\circ}$ profile ${ }^{\circ}$ of ${ }^{\circ}$ time ${ }^{\circ}$ at ${ }^{\circ}$ which the intensity of $\mathrm{H}_{3} \mathrm{ATP}^{-}$reached its maximum value in the on-line EC/ESMS experiments for each film thickness $^{\circ}$ versus $^{\circ}$ film $^{\circ}$ synthesis ${ }^{\circ}$ time.${ }^{\circ}$ From $^{\circ}$ Figure $^{\circ} 6{ }^{\circ},{ }^{\circ}$ it $^{\circ}$ is observed that the amount of ATP released is proportional to the film synthesis time up to $30 \mathrm{~min}$. Before 30 min, the total amount of ATP released could also be adjusted by controlling the membrane thickness, providing $^{\circ}$ the ${ }^{\circ}$ polymer $^{\circ}$ remained $^{\circ}$ electroactive ${ }^{\circ}[29]^{\circ} .^{\circ}$ The longer the time of electropolymerizing the film, the more ATP that was entrapped into the film, and thus more could be released during the reduction. From a synthesis time of $30 \mathrm{~min}$ onward, the relative ion intensity of the film at $\mathrm{m} / \mathrm{z} 506$ decreased. There is evidence from the literature that thicker films become less ${ }^{\circ}$ lectroactive [9], ${ }^{\text {w which }}$ leads to $^{\circ} \mathrm{ess}^{\circ} \mathrm{ATP}{ }^{\circ}$ entrapped in the polymer film, and thus less ATP would be released from the film during the reduction. We also observed that the release time at which the peak intensity at $m / z 506$ reached its maximum value for each film thickness increased with film synthesis time. For a synthesis time of $30 \mathrm{~min}$, the film was much less electroactive, so the maximum release time increased sharply. We suggest that thicker film has greater resistance after it has lost electroactivity. Thus, a smaller current passes through the film and it has slower ion compensation, which produces a slower release rate.

\section{Conclusion}

For the convenience of ATP detection in the EC/ESMS experiment, the best conditions were found at $\mathrm{CH}_{3} \mathrm{CN}$ / 
$\mathrm{H}_{2} \mathrm{O} / \mathrm{Et}_{3} \mathrm{~N}$ (vol/vol/vol $=35 / 65 / 0.1$ ) with $2 \mathrm{mM}$ $\mathrm{NH}_{4} \mathrm{Ac}$ as the supporting electrolyte. Under these conditions, ATP could be released during the potential cycling process, and the results show a significant electrochemical ATP release in a relatively short time. The parent ions (ATP molecular ion $\mathrm{m} / \mathrm{z}=506$ ) and these offspring ions $(\mathrm{m} / \mathrm{z}=426,328,257,159)$ have very similar release profiles, indicating that ATP fragmentation occurs in the electrospray process. In addition, it is noticed that slow potential cycling allowed a higher ATP release rate than did a rapid potential step. Therefore, by carefully controlling potential, the ATP release rate is adjustable. In addition, the film thickness is an important factor affecting both the rate and the amount of electrochemical ATP release.

\section{Acknowledgments}

The authors acknowledge the staff of Tsinghua University Department of Environmental Science \& Engineering for support and M. Wyatt Yiting Mi and Sheng Xu for comments on the manuscript.

\section{References}

1. Reynolds, J. R.; Pyo, M.; Qiu, Y. J. Cation and Anion Dominated Ion Transport During Electrochemical Switching of Polypyrrole Controlled by Polymer-Ion Interactions. Synth. Met. 1993, 55, 1388-1395.

2. Qiu, Y. J.; Reynolds, J. R. Electrochemically Initiated Chain Polymerization of Pyrrole in Aqueous Media. Polym. Eng. Sci. 1991, 31, 417-421.

3. Tsai, E. W.; Pajkossy, T.; Rajeshwar, K.; Reynolds, J. R. Anion-exchange Behavior of Polypyrrole Membranes. J. Phys. Chem. 1988, 92, 3560-3565.

4. Genies, E. M.; Bidan, G.; Diaz, A. F. Spectroelectrochemical Study of Polypyrrole Films. J. Electroanal. Chem. 1983, 149, 101-113.

5. Schlenoff, J. B.; Chien, J. C. W. Mass Transport in Polyacetylene and Polypyrrole Measured by Ion Self-exchange. J. Am. Chem. Soc. 1987, 109, 6269-6274.

6. Pyo, M.; Reynolds, J. R. Poly(pyrrole adenosine 5'-triphosphate) (PP-ATP) and Conducting Polymer Bilayers for Transport of Biologically Active Ions. Synth. Met. 1995, 71, 2233-2236.

7. Pyo, M.; Maeder, G.; Kennedy, R. T.; Reynolds, J. R. Controlled Release of Biological Molecules from Conducting Polymer Modified Electrodes. J. Electroanal. Chem. 1994, 368, 329-332.

8. Boyle, A.; Genies, E.; Fouletier, M. Electrochemical Behavior of Polypyrrole Films Doped with ATP Anions. J. Electroanal. Chem. 1990, 279, 179-186.

9. Genies, E. M.; Pernaut, J. M. Spectroelectrochemical Studies of the Redox and Kinetic Behavior of Polypyrrole Film. Synth. Met. 1984, 10, 117-129.

10. Pyo, M.; Demoustier, S.; Reynolds, J. R. Ion Transport During Redox Switching of Conducting Polymers and Conducting Polymer Bilayers. Polym. Prepr. (American Chemical Society, Division of Polymer Chemistry) 1994, 35, 240-241.
11. Pyo, M.; Reynolds, J. R. Electrochemically Stimulated Adenosine 5'-Triphosphate (ATP) Release through Redox Switching of Conducting Polypyrrole Films and Bilayers. Chem. Mater. 1996, 8, 128-133.

12. Abraham, E. H.; Salikhova, A. Y.; Hug, E. B. Critical ATP Parameters as Associated with Blood and Mammalian Cells: Relevant Measurement Techniques. Drug Dev. Res. 2003, 59, 152-160.

13. Genies, E. M.; Syed, A. A. Polypyrrole and Poly(N-methylpyrrole)-An Electrochemical Study in an Aqueous Medium. Synth. Met. 1984, 10 21-30.

14. (a) Wong, J. W.; Langer, R.; Ingber, D. E. Electrically Conducting Polymers Can Noninvasively Control the Shape and Growth of Mammalian Cells. Proc. Natl. Acad. Sci. U.S.A. 1994, 91, 3201-3204. (b) Schmidt, C. E.; Shastri, V. R.; Vacanti, J. P.; Langer, R. Stimulation of Neurite Outgrowth Using an Electrically Conducting Polymer. Proc. Natl. Acad. Sci. U.S.A. 1997, 94, 8948-8953. (c) Garner, B.; Hodgson, A. J. Wallace, G. G.; Underwood, P. A. Human Endothelial Cell Attachmen to and Growth on Polypyrrole-Heparin Is Vitronectin Dependent. I. Mater. Sci. Mater. Med. 1999, 10, 19-27.

15. Li, Y.; Dong, S. Electrochemically Controlled Release of Adenosine 5'-Triphosphate from Polypyrrole Film. J. Chem. Soc. Chem. Commun. 1992, 11, 827-828.

16. Liljegren, G.; Forsgard, N.; Zettersten, C.; Pettersson, J.; Svedberg, M. Herranen, M.; Nyholm, L. On-line Electrochemically Controlled Solidphase Extraction Interfaced to Electrospray and Inductively Coupled Plasma Mass Spectrometry. Analyst 2005, 130, 1358-1368.

17. Kertesz, V.; Van Berkel, G. J. Monitoring Ionic Adducts to Elucidate Reaction Mechanisms: Reduction of Tetracyanoquinodimethane and Oxidation of Triphenylamine Investigated Using On-line Electrochemistry/ Electrospray Mass Spectrometry. J. Solid State Electrochem. 2005, 9, 390-397.

18. Deng, H.; Van Berkel, G. J. Electrochemical Polymerization of Aniline Investigated Using On-line Electrochemistry/Electrospray Mass Spectrometry. Anal. Chem. 1999, 71, 4284-4293.

19. Zhou, F.; Van Berkel, G. J. Electrochemistry Combined Online with Electrospray Mass Spectrometry. Anal. Chem. 1995, 67, 3643-3649.

20. Pretty, J. R.; Van Berkel, G. J. Electrochemical Sample Pretreatment Coupled Online with Electrospray Mass Spectrometry for Enhanced Elemental Analysis, Rapid Commun. Mass Spectrom. 1998, 12, 1644-1652.

21. Pretty, J. R.; Deng, H.; Goeringer, D. E.; Van Berkel, G. J. Electrochemically Modulated Preconcentration and Matrix Elimination for Organic Analytes Coupled On-line with Electrospray Mass Spectrometry. Anal. Chem. 2000, 72, 2066.

22. $\mathrm{Xu}, \mathrm{X}$ : Lu, W. Cole, R. B. Online Probe for Fast Electrochemistry Electrospray Mass Spectrometry. Investigation of Polycyclic Aromatic Hydrocarbons. Anal. Chem. 1996, 68, 4244-4253.

23. Lu, W.; Xu, X.; Cole, R. B. Online Linear Sweep VoltammetryElectrospray Mass Spectrometry. Anal. Chem. 1997, 69, 2478-2484.

24. Van Berkel, G. J. The Electrolytic Nature of Electrospray. In Electrospray Ionization Mass Spectrometry: Fundamentals, Instrumentation, and Applications, Cole, R. B., Ed.; John Wiley: New York, 1997; pp 65-105.

25. Kertesz, V.; Dunn, N. M.; Van Berkel, G. J. Electrochemistry-ElectrosprayMass Spectrometry Study of Cesium Uptake in Nickel Hexacyanoferrate Films. Electrochim. Acta 2002, 47, 1035-1042.

26. Liljegren, G.; Dahlin, A.; Zettersten, C.; Bergquist, J.; Nyholm, L. On-line Coupling of a Microelectrode Array Equipped Poly(dimethylsiloxane) Microchip with an Integrated Graphite Electrospray Emitter for Electrospray Ionization Mass Spectrometry. Lab on a Chip 2005, 5, 1008-1016.

27. Cole, R. B.; Ed. Electrospray Ionization Mass Spectrometry: Fundamentals, Instrumentation, and Applications; Wiley: New York, 1997.

28. Van Berkel, G. J.; Zhou, F. Electrospray as a Controlled-current Electrolytic Cell: Electrochemical Ionization of Neutral Analytes for Detection by Electrospray Mass Spectrometry. Anal. Chem. 1995, 67, 3958-3964.

29. Pernaut, J.; Reynolds, J. R. Use of Conducting Electroactive Polymers for Drug Delivery and Sensing of Bioactive Molecules. A Redox Chemistry. J. Phys. Chem. B 2000, 104, 4080-4090. 